\title{
PROGNOSTIC FACTORS FOR INVASIVE THYMOMA TREATED WITH RADIATION THERAPY ALONE OR COMBINATION OF SURGERY AND RADIATION THERAPY
}

\author{
Yoshihiro Saito, Kazushige Hayakawa, Yoshio Tamaki, \\ Iwao Hashida, Masaya Furuta, Katsuya Maebayashi, \\ Reiko Imai, Norio Mitsuhashi, Hideo Niibe \\ Department of Radiology and Radiation Oncology \\ Gunma University School of Medicine 3-39-22, Showa-machi, Maebashi, Gunma 371, Japan
}

\begin{abstract}
The prognostic factors and the correlation between local control and total dose were investigated for the patients with invasive thymoma treated by a combination of radiation therapy and surgery or radiation therapy alone. Eighteen patients were retrospectively analyzed. Our treatment strategy was to give the target volume a total dose of at least $50 \mathrm{~Gy}$ for patients with microscopic residual and $60 \mathrm{~Gy}$ or more for macroscopic residual. The actuarial survival rates were $61 \%$ at 5 years and $54 \%$ at 10 years in all patients. All patients having a complete resection survived disease-free for more than 6 years while the survival rates of patients with macroscopic residual or unresected tumors were $38 \%$ at 5 years and $25 \%$ at 10 years $(\mathrm{p}<0.005)$. For macroscopic residual local recurrence rate within a radiation field was $0 \%$ at a dose of $60 \mathrm{~Gy}$ or more, $67 \%$ from 50 to $58 \mathrm{~Gy}$ and $100 \%$ under $40 \mathrm{~Gy}$, respectively. Invasive thymoma may be preferable to be treated at the dose of $50 \mathrm{~Gy}$ or more for microscopic residual and $60 \mathrm{~Gy}$ or more for macroscopic residual. Good prognosis may be expected in the patients undergoing complete resection and radiation therapy.
\end{abstract}

Key words : Invasive thymoma, Radiation therapy, Operation, Local control, Prognosis (Kitakanto Med.J. 47 (1) : 19 23, 1997)

\section{INTRODUCTION}

Thymoma, the morphologic criteria of which was defined by Rosai and Levine ${ }^{1}$, is the most common neoplasm found in the anterior mediastinum ${ }^{2}$. It is a slow-growing tumor with a local invasion and rarely metastasizes outside the thorax ${ }^{3)}$. Good prognosis, such as survival rates of $75-100 \%$ at 5 -years and 63 $-100 \%$ at 10 -years, was reported in patients with noninvasive tumors ${ }^{3 \sim 6)}$. In invasive tumors, survival rates were about $50-73 \%$ at 5 years and $30-60 \%$ at 10 years, respectively ${ }^{4 \sim 8)}$. On the other hand, thymic carcinoma recognized by a high degree of histologic anaplasia and close resemblance to carcinomas are distinguished from thymoma ${ }^{9 \sim 11)}$. Treatment strategy and prognosis are very different in these tumors. The complete resec- tion is the treatment of choice though sometimes it is impossible because of invasion to surrounding structures. A tumor relapse may be observed in $0-12 \%$ of non-invasive thymoma ${ }^{3 \sim 6,12 \sim 13)}$. Even if complete resection is performed, approximately $20 \%$ of invasive thymoma may recur locally ${ }^{4}$. It remains controversial whether postoperative irradiation is necessary for the patients receiving complete resection ${ }^{4,6,7}$. However, radiation therapy has been recommended for the patients with postoperative residual tumors ${ }^{4,6,7,14,15)}$. The purpose of this article is to present the prognostic factors and the correlation between local control and total dose in the patients with invasive thymoma treated by our treatment strategy.

Received : October 29, 1996

Address: YOSHIHIRO SAITO OR HIDEO NIIBE

Department of Radiology and Radiation Oncology, Gunma University School of Medicine

3-39-22, Showa-machi, Maebashi, Gunma 371, Japan 


\section{MATERIALS AND METHODS}

There were eighteen patients with invasive thymoma treated in our department from 1973 to 1989. Their initial investigation and surgery had been performed at surgical departments in our or other hospitals prior to consultation with our department. Twelve patients were male and six female. Mean age was 59 years with a range of 34 to 74 years.

\section{Pathology and Staging}

Tumors were classified to epithelial, lymphocytic and mixed type according to the predominant cell type. All patients were staged according to the classification of MASAOKA ${ }^{5}$ (Table 1) except for two patients who did not undergo thoracotomy (Table 2). There were two patients with Stage II invading only pleura and twelve with Stage III invading a lung or an adjacent vasculature and two with Stage IV having pleural dissemination. Myasthenia gravis was associated in 5 of 18 patients.

\section{Surgery}

Eight patients had a complete resection and three had an incomplete resection. Four patients had only open biopsy.

\section{Radiation therapy}

Eight patients, including four with open biopsy and one undergoing radiation therapy because of recurrence after surgery, were treated with radiation

Table 1 Clinical Stages by Masaoka

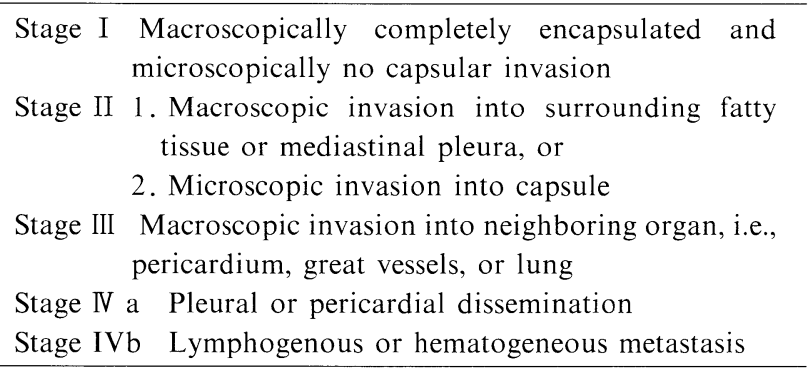

therapy alone. Eight patients with complete resection and two with incomplete resection assessed by surgical inspection were treated with radiation therapy after surgery (Table 2). Radiation therapy was given with a $10 \mathrm{MeV}$ linear accelerator. Anterior fields or anteroposterior parallel opposed fields weighted $2: 1$ were employed by tumor sites. The fraction size was $2 \mathrm{~Gy} /$ day. The treatment volume encompassed all tumors visible on pre-treatment chest radiographs with a 1 to $2 \mathrm{~cm}$ margin when a tumor was incompletely resected. When a tumor was completely resected the radiation field included pleura and pericardium adjacent to tumor. After $40 \mathrm{~Gy}$, the radiation field was decreased to include the most possible residual tumor site as the dose of the spinal cord was under $50 \mathrm{~Gy}$ with a fraction size of 1.4 to $1.8 \mathrm{~Gy}$. From 1980, computed tomography has been used in 14 patients for the confirmation of treatment volume. Our treatment strategy is to give the target a total dose of at least 50 Gy for patients with microscopic residual tumors and 60 Gy or more for macroscopic residual tumors. The target dose given varied from 50 to $70 \mathrm{~Gy}$ (mean $57 \mathrm{~Gy}$ ) except for two under 40 Gy because at first these patients were diagnosed as a lymphoma. Two patients received 70 Gy because a tumor shadow remained on chest radiography.

Survival curves were calculated by the KaplanMeier method. The curve was not age-adjusted and the death from unknown reason was calculated as cancer death. The comparisons between the curves were obtained by logrank test. The minimum follow-up period was 6 years.

\section{RESULTS}

The actuarial survival rates were $61 \%$ at 5 years and $54 \%$ at 10 years in all patients (Fig. 1.). Two patients with Stage II disease undergoing a complete resection survived disease-free for more than 6 years. For twelve

Table 2 Patients Characteristics and Prognosis

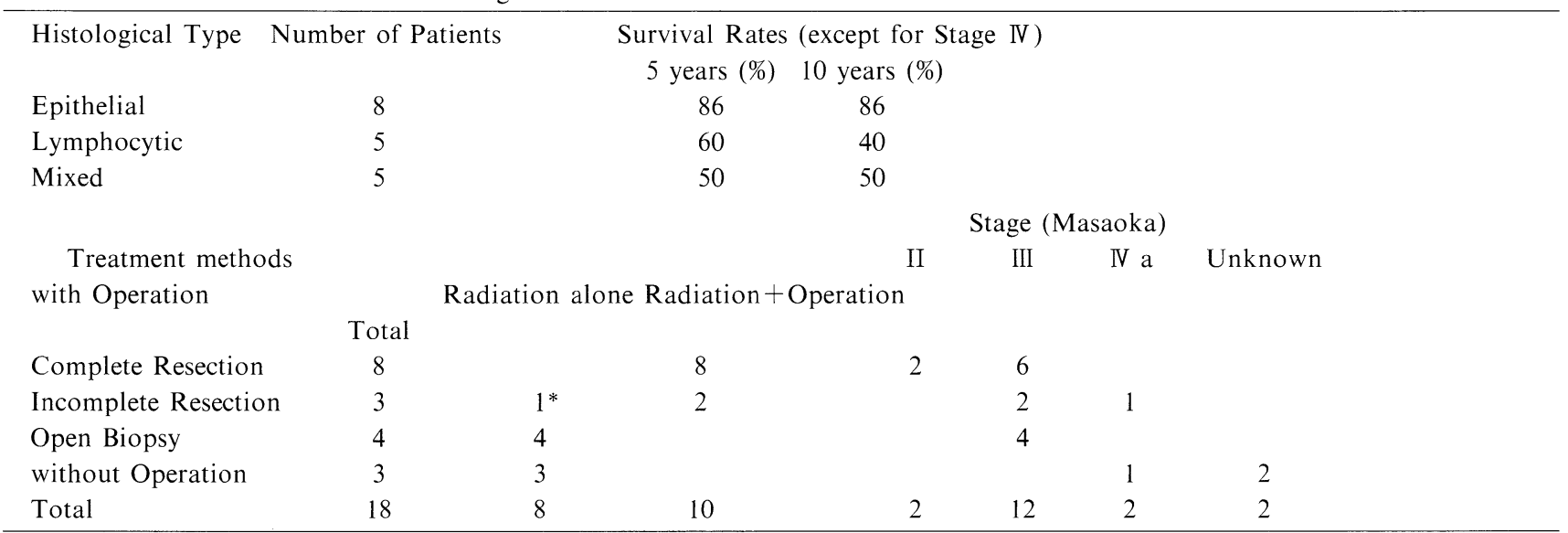

*This patient was treated with radiation therapy due to recurrence after surgery. 


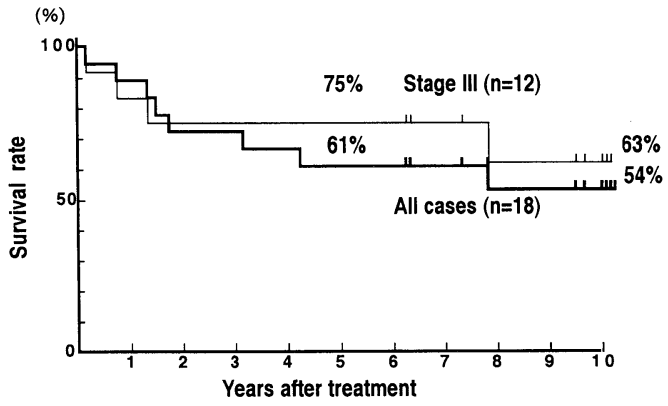

Fig. 1. Cumulative survival curves for all patients and patients with Stage III disease

patients with Stage III disease who underwent a complete resection in $50 \%$ of them, survival rates were $75 \%$ at 5 years and $63 \%$ at 10 years, respectively. Two patients with Stage IV disease died of thymoma at 18 and 38 months after radiation therapy. All patients having a complete resection survived disease-free while the survival rates of Stage III patients having macroscopic residual tumors or unresected tumors were $38 \%$ at 5 years and $25 \%$ at 10 years, respectively (Fig. 2., p $<$ 0.005). In histological types survival rates of Stage II or III patients were $86 \%$ for epithelial type, $60 \%$ for lymphocytic type and $50 \%$ for mixed type at 5 years and $86 \%, 40 \%$ and $50 \%$ at 10 years, respectively (Table 2). Myasthenia gravis did not have a significant impact on treatment outcome.

In Stage II or III disease, infield recurrence rates for microscopic residual tumors were $0 \%$ at a dose of 50 Gy or more. Those for macroscopic residual tumors were $0 \%$ at $60 \mathrm{~Gy}$ or more, $67 \%$ at $50-58 \mathrm{~Gy}$ and $100 \%$

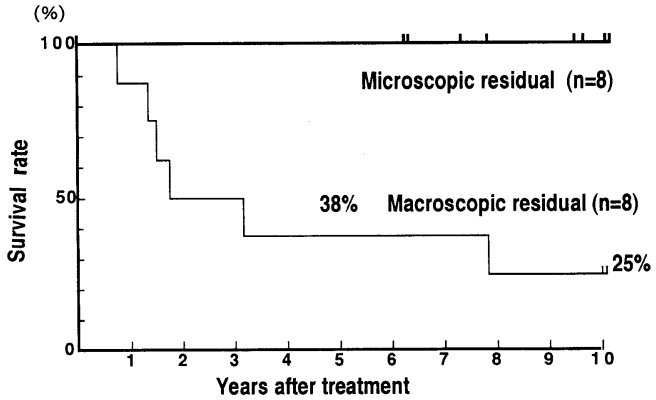

Fig. 2. Cumulative survival curves by the extent of operation

less than $40 \mathrm{~Gy}$, respectively (Table 3 ). Two patients treated less than $40 \mathrm{~Gy}$ were diagnosed as a malignant lymphoma at first. Intrathoracic recurrences were seen in seven patients, in whom five infield recurrences were included, and distant recurrence in four (two pulmonary metastases, one bone metastasis and one axillary lymph node metastasis) (Table 4). There were 11 patients who survived for more than 5 years (Table 5). Almost all patients had slight radiation esophagitis unnecessary for treatment. No serious radiation se-

Table 3 In-field Recurrence Rate by Total Dose

\begin{tabular}{lccc}
\hline Total Dose & \multicolumn{2}{c}{ Infield Recurrence Rate } \\
& Microscopic residual & Macroscopic residual & Total \\
\hline$\sim 40 \mathrm{~Gy}$ & & $2 / 2(100 \%)$ & 2 \\
$50 \sim 58 \mathrm{~Gy}$ & $0 / 5(0 \%)$ & $2 / 3(67 \%)$ & 8 \\
60Gy & $0 / 3(0 \%)$ & $0 / 2(\quad 0 \%)$ & 5 \\
Total & 8 & 7 & 15 \\
\hline
\end{tabular}

Three patients were excluded from analysis because of Stage IV or uncertain records.

Table 4 Pattern of Failure by the Extent of Operation

\begin{tabular}{|c|c|c|c|c|c|}
\hline \multirow[t]{2}{*}{ Operation } & \multirow[t]{2}{*}{ Number of patients } & \multicolumn{3}{|c|}{ Recurrence } & \multirow[t]{2}{*}{ Unknown } \\
\hline & & $\begin{array}{l}\text { Intrathoracic } \\
\text { Infield ( ) }\end{array}$ & Distant & Both & \\
\hline Complete & 8 & 0 & 0 & 0 & 0 \\
\hline $\begin{array}{l}\text { Incomplete or } \\
\text { Open Biopsy }\end{array}$ & 7 & $4(3)$ & 1 & $1(1)$ & 1 \\
\hline without Operation & 3 & $1(1)$ & 1 & 1 & 0 \\
\hline Total & 18 & $5(4)$ & 2 & $2(1)$ & 1 \\
\hline
\end{tabular}

Table 5 Characteristics of 5-Year Survivors

\begin{tabular}{cccllll}
\hline \multicolumn{2}{c}{ Sex/Age } & Stage & Histological type & Operation & Radiotherapy & Prognosis \\
\hline 1 & $\mathrm{~F} / 47$ & II & mixed & complete & after surgery & alive with disease-free \\
2 & $\mathrm{M} / 63$ & II & lymphocytic & complete & after surgery & alive with disease-free \\
3 & $\mathrm{M} / 45$ & III & epithelial & complete & after surgery & alive with disease-free \\
4 & $\mathrm{~F} / 72$ & III & epithelial & complete & after surgery & alive with disease-free \\
5 & $\mathrm{M} / 44$ & III & epithelial & complete & after surgery & alive with disease-free \\
6 & $\mathrm{M} / 69$ & III & epithelial & complete & after surgery & alive with disease-free \\
7 & $\mathrm{M} / 71$ & III & epithelial & complete & after surgery & alive with disease-free \\
8 & $\mathrm{M} / 62$ & III & mixed & complete & after surgery & alive with disease-free \\
9 & $\mathrm{M} / 34$ & III & lymphocytic & incomplete & recurrence & dead with local recurrence \\
10 & $\mathrm{M} / 54$ & III & lymphocytic & biopsy & alone & dead with local and distant recurrence \\
11 & $\mathrm{M} / 55$ & III & epithelial & biopsy & alone & alive with distant metastases \\
\hline
\end{tabular}


quela was seen in any of the patients.

\section{DISCUSSION}

Irradiation following surgery has been reported to be necessary for invasive thymoma ${ }^{4,6,15,16)}$. The outcome of our patients with invasive thymoma was similar to those in previous reports ${ }^{3,4,7,8}$. Patients, who had a complete resection or had Stage II disease, were locally controlled for a long-term though patients with an incomplete resection were not. The extent of operation and stage of disease were already reported to be important prognostic factors ${ }^{3,4,7,12,16 \sim 18)}$. Pollack et al. ${ }^{19)}$ and Mornex et al. ${ }^{20)}$ reported the patients with the incomplete resection had a better prognosis than those with biopsy though in some papers a debulking operation followed by irradiation did not have better survival benefits than a radiation therapy alone ${ }^{16,18,21)}$. In our data no difference of survivals was seen between the patients who had an incomplete resection and those who had only biopsy. Intra-thoracic recurrence which resulted from local invasion or pleural dissemination was recognized in the patients with these advanced tumors.

Urgesi $^{22)}$ reported that infield relapses after irradiation correlated with the type of resection. He did not mention anything about the correlation between infield recurrence and total dose. The optimal dose for controlling microscopic or macroscopic residual tumor was controversial. Pollack et al. ${ }^{19)}$ and Mornex et al. ${ }^{20)}$ recommended $50 \mathrm{~Gy}$ for completely resected invasive thymoma and more than 50 Gy for unresectable tumors. In our data, a total dose less than $60 \mathrm{~Gy}$ was insufficient for the eradication of macroscopic residual tumors. For microscopic residual no infield recurrence was observed at a dose of $50 \mathrm{~Gy}$ or more, suggesting these doses may be preferable to sterilize microscopic residual tumors.

No clear difference of prognosis was seen by histological subtypes. Prognosis for the patients with epithelial type may be superior to those with other histological types due to different numbers of complete resection which is larger in epithelial type. So far, histological subtypes have been reported not to correlate with prognosis ${ }^{4,16,18,22)}$ though some papers suggested that the predominant epithelial type with an exception of the spindle cell variant carried a worse progno$\operatorname{sis}^{8)}$. Marino and müller-Hermelink ${ }^{23)}$ proposed a new classification which classified thymoma into cortical, medullary and mixed type from cytological similarity to normal cortical and medullary epithelial cells. Ricci $^{24)}$ and other authors ${ }^{25)}$ reported medullary thymoma was better prognosis than cortical thymoma and mixed type was intermediate prognosis by a new classification.

There were four patients with distant metastases in our data. Distant metastases were rare, in about 3-26\% and much more in advanced cases ${ }^{3,7,18)}$. In advanced cases reduction surgery may be ineffective in prognosis because of pleural dissemination or distant metastases.

Jackson $^{7)}$ reported that three patients (11\%) developed significant side effects by radiation therapy. No serious radiation sequela such as radiation myelopathy or severe radiation pneumonitis was seen in any of our patients.

In conclusion, invasive thymoma may be preferable to be treated at the dose of 50 Gy or more for microscopic residual tumor and $60 \mathrm{~Gy}$ or more for macroscopic residual tumor. A fruitful outcome will be expected by undergoing complete resection and radiation therapy.

\section{REFERENCES}

1) Rosai J, Levine GD: Tumors of the thymus. In : Atlas of tumor pathology 2 nd series, Fascicle 13. Armes. Forces Institute of Pathology. Washington 1976.

2) Wada H, Teramatsu $T$ : Mediastinal tumors: A statistical nationwide report of 1,546 cases between July, 1975 and May, 1979 in Japan. J Japanese Associ Thorac Surg 1982 ; 30 : 374-378.

3) Lewis JE, Wick MR, Taylor WF, et al. Thymoma: A clinicopathologic review. Cancer $1987 ; 60: 2727-2743$.

4) Maggi G, Casadio C, Ruffini E, et al. Thymoma : Results of 241 operated cases. Ann Thorac Surg $1991 ; 51: 152-156$.

5) Masaoka A, Monden Y, Tanioka T, et al. Follow up study of thymomas with special reference to their clinical stages. Cancer $1981 ; 48: 2485-2492$.

6) Nordstrom DG, Tewfik HH, Latourette HB : Thymoma: Therapy and prognosis as related to operative staging. Int $\mathrm{J}$ Radiat Oncol Biol Phys $1979 ; 5$ : 2059-2062.

7) Jackson MA, Ball DL : Post-operative radiotherapy in invasive thymoma. Radiother Oncol 1991; $21: 77-82$.

8) Verley JM, Hollmann KH : A comparative study of clinical stages, histologic features, and survival in 200 cases. Cancer $1985 ; 55: 1074-1086$.

9) Shimosato Y, Kameya T, Suemasu K, et al. Squamous cell carcinoma of the thymus. An analysis of eight cases. Am J Surg Pathol 1977 ; 1 : 109-121.

10) Snover DC, Levine GD, Rosai J : Thymic carcinoma. Five distinctive histological variants. Am J Surg Pathol $1982 ; 6: 451-470$. 
11) Wick MR, Weiland LH, Bernatz PE, et al. Primary thymic carcinomas. Am J Surg Pathol 1982 ; $6: 613-630$.

12) Curran WJ, Kornstein MJ, Turrisi AT, et al. Invasive thymoma: The role of mediastinal irradiation following complete or incomplete surgical resection. J Clin Oncol 1988; 6 : 1722-1727.

13) Fechner RE: Recurrence of noninvasive thymomas: Report of four cases and review of literature. Cancer $1969 ; 23: 1423-1427$.

14) Ariaratnam LS, Kalnicki S, Botstein C, et al. The management of malignant thymoma with radiation therapy. Int J Radiat Oncol Biol Phys 1979 ; $5: 77-80$.

15) Gerein AN, Srivastava SP, Burgess J : Thymoma : A ten year review. The American Journal of Surgery $1978 ; 136: 49-53$.

16) Gamondes JP, Balawi A, Maret G, et al. Seventeen years of surgical treatment of thymoma: Factors influencing survival. Eur J Cardio-thorac surg $1991 ; 5: 124-131$.

17) Bergh NP, Gatzinsky P, Ridell B, et al. Tumors of the thymus and thymic region: 1 . Clinicopathological studies on thymomas. Ann Thorac Surg $1978 ; 25: 91-98$.

18) Cohen DJ, Ronningen LD, Zajtchuk R, et al. Management of patients with malignant thymoma. J Thorac Cardiovasc Surg 1984; 87 : 301-307.

19) Pollack A, Komaki R, Cox JD, et al. Thymoma :
Treatment and prognosis. Int $\mathbf{J}$ Radiat Oncol Biol Phys $1992 ; 23$ : 1037-1043.

20) Mornex F, Resbeut M, Nguyen TD, et al. Radiotherapy and chemotherapy for invasive thymomas: A multicentric retrospective review of 90 cases. Int J Radiat Oncol Biol Phys 1995; 32 : 651-659.

21) Marks RD, Wallace KM, Pettit HS: Radiation therapy control of nine patients with malignant thymoma. Cancer 1978; $41: 117-119$.

22) Urgesi A, Monetti U, Casadio C, et al. Role of radiation therapy in locally advanced thymoma. Radiother Oncol 1990; 19 : 273-280.

23) Marino M, Müller-Hermelink HK : Thymoma and thymic carcinoma. Relation of thymoma epithelial cell to the cortical and medullary differentiation of thymus. Virchows Arch (A). 1985 ; 407 : 119-149.

24) Ricci C, Rendina EA, Baroni CD, et al. Correlations between histological type, clinical behaviour, and prognosis in thymoma. Thorax 1989; $44: 455-460$.

25) Nomori $H$, Ishihara $T$, Torikata $C$ : Morphometrical and immunohistochemical analysis of cortical and medullary thymoma: its correlation with invasiveness and association with myasthenia gravis. J Japanese Associ Thorac Surg 1990; 38 : 93-100. 